\title{
Removal of fractured implant screws: case report
}

\author{
Tae-Su Kim, Jae-Hyun Lee, Won-Sup Lee, Su-Young Lee* \\ Department of Prosthodontics, Seoul St. Mary's Hospital, The Catholic University of Korea, Seoul, Republic of Korea
}

Screw loosening and screw fracture of abutment is one of most frequent mechanical complications in implant restoration. Fractured fragments in implant restoration like abutment and screw should be completely removed and the procedure needs minimal damage to the fixture of implant. In some cases, it could fail to remove fractured fragments and cause a lot of damage to the fixture of implant. These situations could render implant unusable at the worst. This article describes three different situations and simple techniques for successful removal of fractured fragments without damage of implants. The procedures used are described in this clinical report. (J Dent Rehabil Appl Sci 2015;31(1):60-6)

Key words: dental implant; screw frature; abutment fracture; screw removal; screw loosening

\begin{abstract}
서론
오늘날 부분 또는 완전 무치악 환자의 보철치료에서 치과용 임플란트가 보편적으로 사용되고 있다. 많은 연 구 $^{1}$ 에서 $90 \%$ 가 넘는 높은 성공률과 생존률을 바탕으로 임플란트 치료의 안정성과 예지성을 인정하고 있지만, 아직까지 많은 경우에서 그 합병증이 발생하고 있다. ${ }^{2}$ 임 플란트 치료의 합병증은 크게 생리적 또는 기술적 합병 증으로 나눌 수 있다. ${ }^{3}$ 생리적 합병증은 임플란트 주위 염, 골흡수 또는 그와 연관된 골유착의 실패 등을 포함하 고, 기술적 합병증은 수복물의 파절 또는 탈락, 지대주 나 사의 풀림 또는 파절, 고정체 또는 지대주의 파절 등을 포함한다. ${ }^{3}$

지대주 나사와 관련하여 나사의 풀림은 비교적 잦은 합병증으로 시멘트 유지형보다 나사 유지형에서, internal type보다 external type에서 높은 것으로 알려져 있 다. ${ }^{4,5}$ 또한 상악보다는 하악에서, 다수치아 수복보다 단 일치 수복인 경우 그 빈도가 높다고 보고되었다. ${ }^{4,5}$ 나사

*Correspondence to: Su-Young Lee

Professor, Department of Prosthodontics, Seoul St. Mary's Hospital, The Catholic University of Korea, 505 Banpo-dong, Seocho-gu, Seoul, 137-040, Republic of Korea Tel: +82-2-2258-6309, Fax: +82-2-537-2374, E-mail: Isuyoung@daum.net Received: October 14, 2014/Last Revision: January 8, 2015/Accepted: February 10,2015
\end{abstract}

가 풀리면 응력이 적절하게 분산되지 않고 특정 부위의 과부하를 야기하여, 이차적으로 나사의 파절을 야기할 수 있다. ${ }^{6-9}$ 나사파절의 경우 나사풀림에 비해 상대적으 로 발생률이 높지 않은 합병증이지만, 나사가 파절된 경 우 반드시 파절편을 제거하고 새로운 나사로 교체하는 것이 필요하다. 나사를 완전히 제거하지 못하는 경우 상 부 보철물 뿐 아니라 골유착된 임플란트까지 사용하지 못하게 되는 경우가 있다. ${ }^{6-9}$

나사파절의 원인 요소들을 살펴보면 과도한 교합력, 부적절한 임플란트 식립위치, 골소실, 이갈이, 이악물기 등의 악습관, 부적절한 보철물의 적합, 보철물의 디자인, 피로누적, 제작결함, 사용된 임플란트의 종류, 형태 및 재 료 등으로 나사파절은 많은 원인요소들에 영향을 받는 다. ${ }^{6-9}$ 특히 잘 맞지 않는 보철물을 제작하는 경우 나사풀 림의 가능성이 증가하고 보철물의 장착 또는 기능 시 나 사가 변형되거나 미세균열이 발생하여 피로파절이 발생 할 가능성이 증가한다. ${ }^{6-9}$

지대주나 나사가 파절된 경우 이를 제거하기 어려운

Copyright@ 2015 The Korean Academy of Stomatognathic Function and Occlusion. (c) It is identical to Creative Commons Non-Commercial License. 
경우가 많은데, 임플란트의 head부위보다 높은 곳에서 파절된 경우 hemostats 등을 이용하여 파절편을 잡고 제 거할 수 있다. ${ }^{10,11}$ 반면에 head 부위보다 낮은 곳에서 파 절된 경우 파절된 나사가 어느 정도 풀려있다면, 근관치 료용 탐침이나 파일, 스케일러 등을 이용하여 제거하는 방법을 시도해 볼 수 있다. ${ }^{12,13}$ 단단하게 고정되어 있는 경우 각 제조회사에서 제공하는 제거용 기구 등을 이용 하거나, ${ }^{14,15}$ 이미 보고된 다양한 technique 등을 이용해 볼 수 있다. Williamson ${ }^{10}$ 은 파절된 나사에 홈을 형성하 고 홈에 맞는 기구를 사용하거나 기구 등을 적절히 변형 시켜 홈에 넣고 나사를 풀러 제거하는 방법을 소개하였 다. ${ }^{10,16}$ Yilmaz 등 ${ }^{17}$ 은 fork-shaped end를 갖는 기구를 이 용하여 나사에 홈을 형성하지 않고 제거하는 방법을 소 개하였다. Pow ${ }^{18}$ 는 나사나 지대주를 제거하는 여러 시도 가 실패하는 경우, 임플란트의 내면을 삭제한 후 주조용 포스트를 제작하여 수복하는 방법을 소개하였다.

본 증례에서는 지대주나 지대주 나사가 파절된 경우 에서 고정체의 손상 없이 성공적으로 부속품을 제거한 사례를 보고하고자 한다.

\section{증례 보고}

\section{1. 증례 1}

61세 남자 환자가 상악 좌측 제 1 대구치의 임플란트 지지 고정성 수복물의 파절을 주소로 가톨릭대학교 서 울성모병원 치과보철과에 내원하였다. 병력청취 상 약 5 년 전 개인치과의원에서 만성치주염 진단 하 치아를 발치하고 임플란트 식립 및 고정성 수복물을 제작한 과 거력이 있었다. 환자는 수개월 전부터 치아가 흔들리 는 증상을 감지하였는데 치료를 받지 않았다고 진술하
였다. 임상적 및 방사선학적 검사 결과 해당 임플란트 는 최후방 단일치아로 수복된 경우로 수복물은 큰 교합 면과 해부학적인 형태로 제작되었다. 식립된 임플란트 는 직경 $7.0 \mathrm{~mm}$, internal-type (Dentium, Seoul, Korea) 으로 완전히 골유착되어 있었으며, 보철 형태는 cement type이었다. 지대주와 지대주 나사의 파절 원인으로는 과도한 기능하중 및 측방력에 의해 나사가 풀리고 반복 하중에 의한 나사와 지대주가 피로파절 된 것으로 추측 되었다.

지대주 일부와 함께 파절된 지대주 나사가 관찰되었 다(Fig. 1). 지대주 나사가 임플란트 head 위치에서 파 절된 경우로 hemostats를 이용하여 제거를 시도하였으 나 제거되지 않았다. High-speed 핸드피스와 1/2-round bur를 이용하여 파절된 나사에 홈을 형성하고 일자 형 태의 드라이버를 인기하여 제거하였다. Bur의 head는 직경 $0.6 \mathrm{~mm}$ 로 고정체가 손상되지 않도록 head가 완전 히 잠길 정도만 삭제하였다(Fig. 2A). 파절된 나사를 제 거 후 부분 파절된 지대주가 제거되지 않아 스케일러와 explorer, file 등을 이용하였지만 제거되지 않았다. 역시 같은 방법으로 지대주 내면에 일부 홈을 형성하여 드라 이버를 인기하여 성공적으로 제거하였다(Fig. 2B).

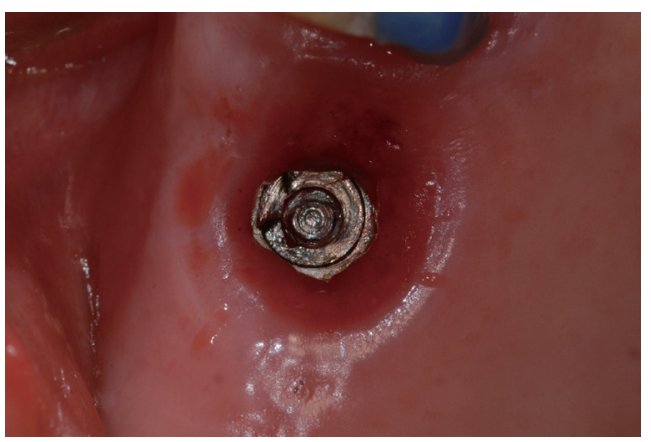

Fig. 1. Fractured abutment \& abutment screw.
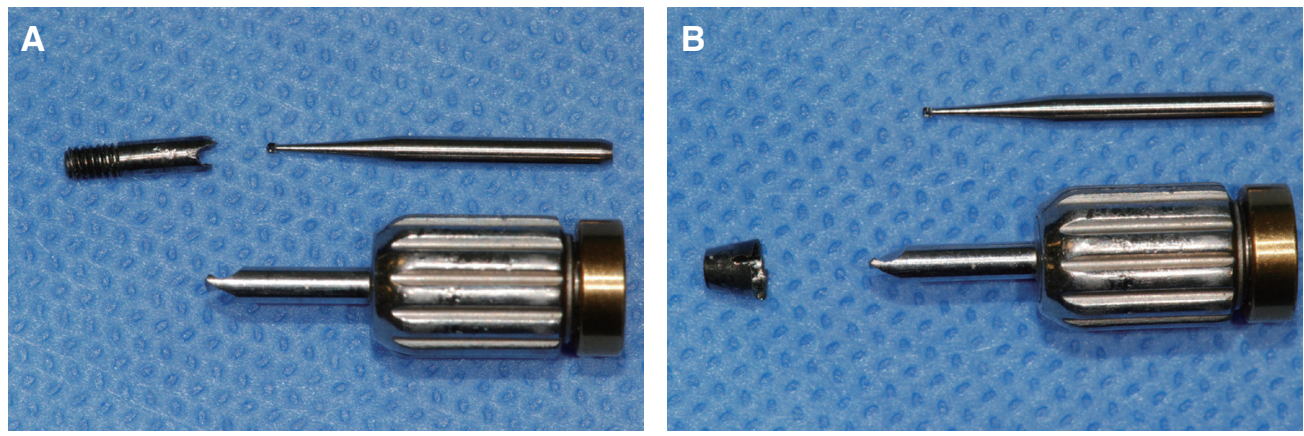

Fig. 2. Removed (A) abutment screw, (B) abutment \& used 1/2-round bur, driver. 


\section{2. 증례 2}

62세 남자 환자가 하악 좌측 제 1 대구치 및 제 2 대구치 의 임플란트 지지 고정성 수복물의 파절을 주소로 가톨 릭대학교 서울성모병원 치과보철과에 내원하였다. 병력 청취 상 약 5 년 전 개인치과의원에서 상기 부위에 임플 란트를 식립하고 고정성 수복물을 제작하였으며, 보철 물 파절 후 재내원하려고 했으나 해당 병원이 없어져 본 원으로 내원하였다. 환자는 그 동안 불편감 없이 사용하 다가 본원 내원 3일 전 파절되었다고 진술 하였다. 임상 적 및 방사선학적 검사 결과 하악 좌측 제 1 대구치 임플 란트의 head 부위에서 나사가 파절되었고, 하악 좌측 제 2대구치 임플란트는 수복물이 탈락하였다(Fig. 3). 제1 대구치의 지대주는 탈락하여 분실되었고, 식립된 임플 란트에 대한 자세한 정보는 얻을 수 없었다.

타 임플란트 시스템에서 제공하는 screw removal kit (Neobiotech, Seoul, Korea)에서 fork-shaped end driver 를 이용하여 파절된 나사의 제거를 시도하였다. 파절된 나사가 풀려있었기 때문에 쉽게 제거될 수 있었다(Fig. 4). 하악 좌측 제 1 대구치의 임플란트 나사가 풀린 채로 기능하다가 파절되고, 하악 좌측 제 2 대구치의 임플란트 수복물이 탈락한 것으로 추측할 수 있었다.

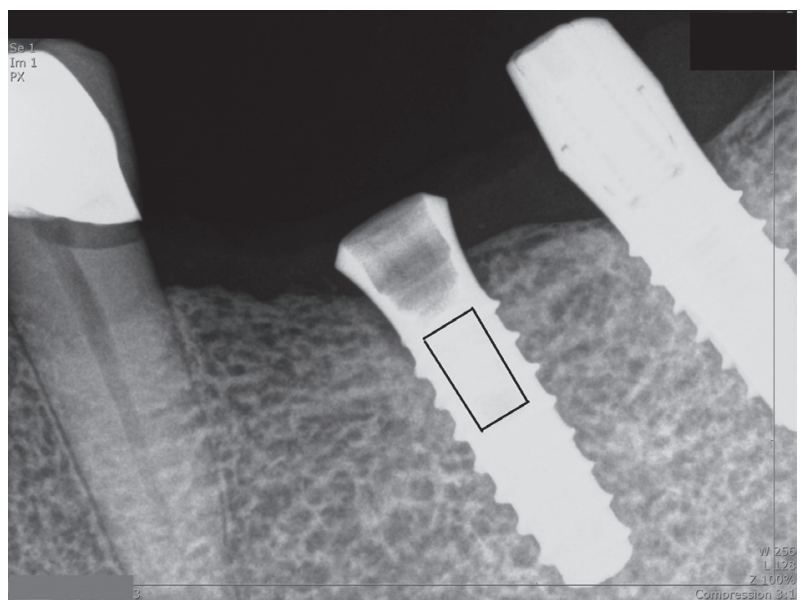

Fig. 3. Radiographic view shows fractured screw in \#36 implant under implant head level \& implant restoration fallen on \#37.

\section{3. 증례 3}

52 세 여자 환자가 하악 좌측 제 1 대구치 및 제 2 대구 치 임플란트가 흔들린다는 주소로 가톨릭대학교 서울 성모병원 치과보철과에 내원하였다. 병력청취 상 약 5 년 전 직경 $5.0 \mathrm{~mm}$ internal type 임플란트(Astratech, Dentsply, Mölndal, Sweden)를 식립하고 multi-지대주를 연결하고, screw type으로 보철 수복을 하였다. 임상적 및 방사선학적 검사 결과 하악 좌측 제 2 대구치의 수복 물 고정나사는 지대주 나사선 하방으로 파절되었으며, 하악 제 1 대구치의 수복물 고정나사는 풀려있었다(Fig. 5). 스케일러와 explorer 등으로 파절된 고정나사를 제거 하고 새로운 나사로 교체하여 수복물을 장착하였다.

약 4 개월 후 수복물 고정나사의 파절을 주소로 재내 원하였다. 임상적 및 방사선학적 검사 결과 하악 제 1,2 대구치의 나사가 모두 파절되었다. 나사가 파절되고 바 로 내원하지 않아 치은이 지대주를 덮고 있었다(Fig. 6). 먼저, 치은성형술을 통해 지대주를 노출시켰다. 직경이 작은 수복물 나사의 사용을 배제하고 수복물의 연결 방 식을 교체하기 위해 multi-지대주의 제거를 시도하였으 나 제거되지 않았다. Case 1의 경우와 비슷하게 Highspeed 핸드피스와 1/2-round bur를 이용하여 지대주에 홈을 형성하고 드라이버를 인기하여 제거하였다(Fig. 7). Bur는 head가 완전히 잠길 정도만 삭제하여 고정체의 손상 없이 지대주를 성공적으로 제거하였다.

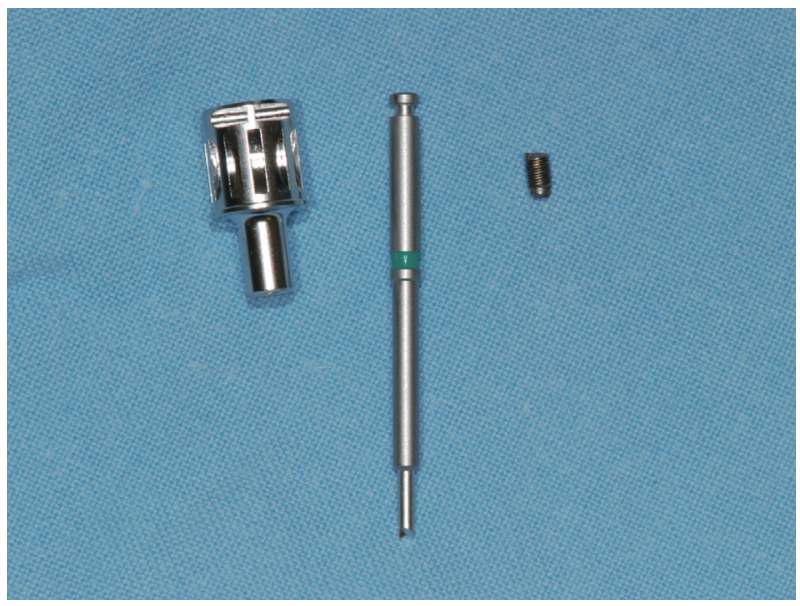

Fig. 4. Removed abutment screw \& used fork-shaped end driver. 

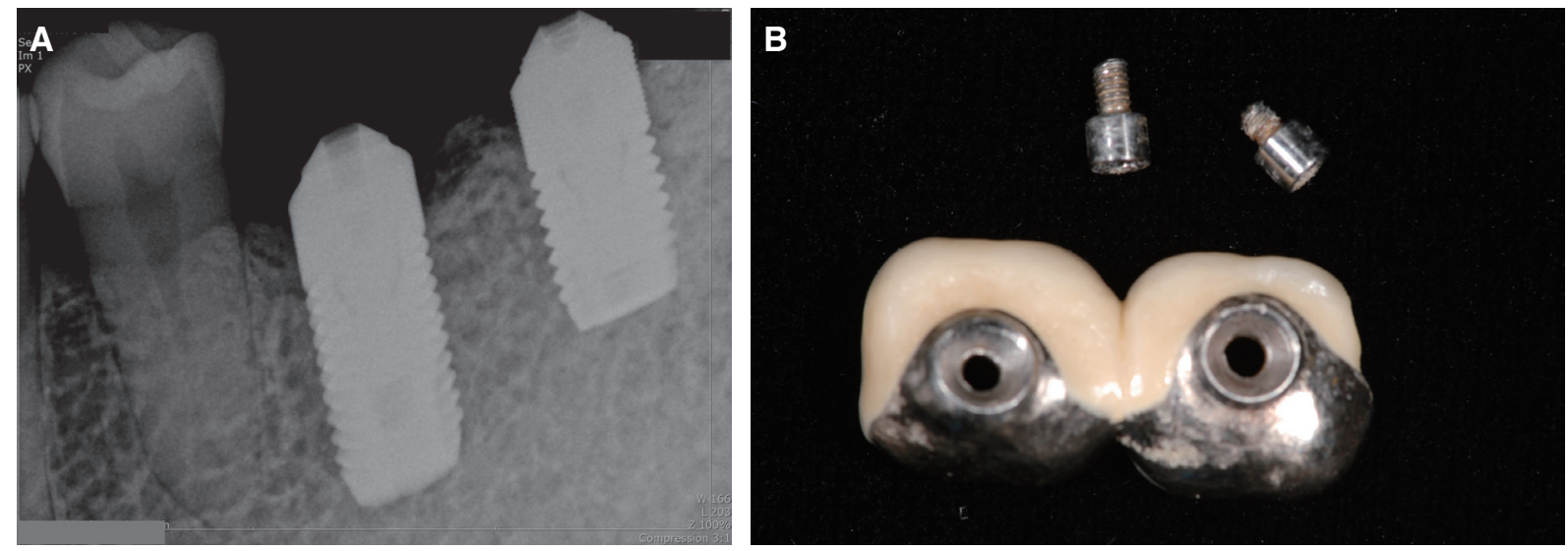

Fig. 5. (A) Radiographic view shows fractured screws in tightened multi-abutments, (B) Removal of fractured multiabutment screws \& implant restoration.
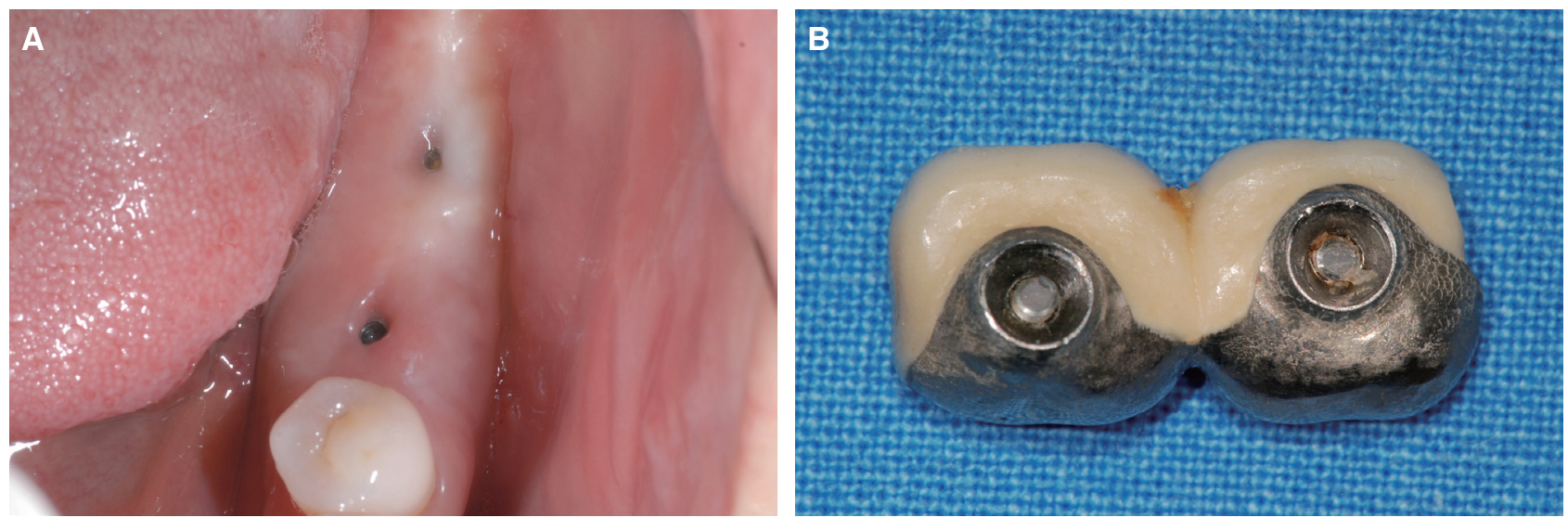

Fig. 6. (A) Screw holes were covered due to gingival overgrowth, (B) Re-fractured multi-abutment screws \& implant restoration.
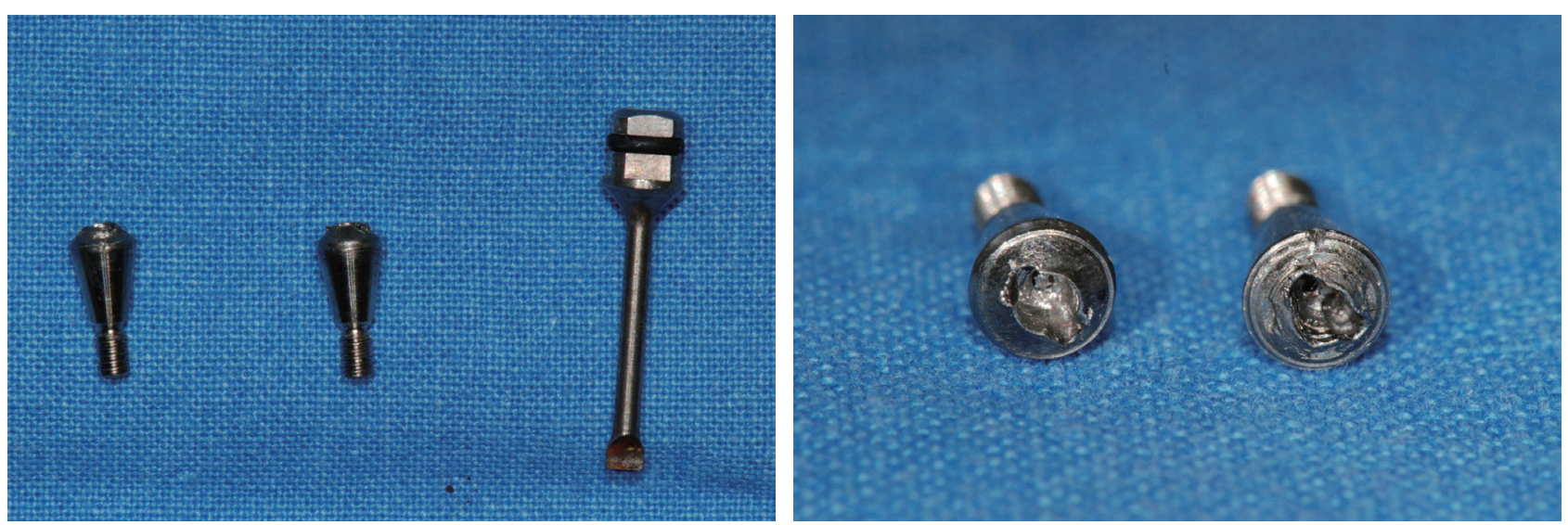

Fig. 7. Removed multi- abutment \& used driver. 


\section{고찰}

나사의 풀림이나 파절은 임상가를 매우 곤란한 상황 에 처하게 할 수 있다. 고정체의 손상 없이 파절편 등을 제거할 수 있다면 문제가 없겠지만, 제거가 되지 않거나 고정체의 나사선 등이 손상되는 경우 재수복이 곤란할 수 있다. 앞서 소개한 주조 포스트 등을 제작하는 방법 이 대안이 될 수 있으나, ${ }^{17}$ 경우에 따라서는 고정체를 제 거해야 할 수도 있다. 따라서, 나사가 풀리거나 파절된 경우 이를 해결할 수 있는 다양한 임상적 접근 방식을 이해하고 숙지할 필요가 있다. ${ }^{10-18}$

나사가 파절되는 과정은 대게 나사가 풀리는 단계로 부터 시작된다고 알려져 있다. 나사가 풀리는 기술적 합 병증을 근본적으로 해결할 수 있는 방법은 아직 알려져 있지 않지만, 주기적인 검진이 그 대안으로 제시될 수 있다. 정기검진 시 나사가 느슨하거나 풀려있는 것이 발 견되면, 이를 나사파절의 경고로 받아들이고 그 원인들 을 조사해볼 필요가 있다. 보철물이 정확하게 장착되었 는지, 과부하를 야기하는 요소들은 없는지, 과도한 측방 력에 노출되어 있는지, 미처 발견하지 못한 악습관 등은 없는지 면밀히 살펴보아야 한다. 경우에 따라서 수복물 의 형태를 조절해 주는 것이 필요할 수 있다. 또한, 특별 한 원인이 없더라도 정착효과로 인해 나사가 풀릴 수 있 다고 알려져 있다. ${ }^{19}$ 이와 더불어 $\mathrm{Al} \mathrm{Jabbari} \mathrm{등}{ }^{6-9}$ 은 반복 하중 시 발생하는 진동에너지가 전하중의 지속적 감소 를 야기하여 나사가 풀릴 수 있다고 지적하였다. 나사가 풀리는 또 다른 원인으로 나사의 기계적 강도의 감소를 들 수 있다. Al Jabbari 등 ${ }^{6-9}$ 은 나사의 조임 시 또는 반복 하중 시 발생하는 나사의 마모, 소성변형, 피로누적 등 은 전하중을 감소시키거나 나사파절의 원인이 될 수 있 다고 보고하였다. 또한 미세한 균열 등의 기계적 결함은 피로누적과 함께 작용하여 나사가 파절되는 주요한 원 인이 될 수 있다.

나사가 느슨해지거나 풀리는 것을 예방하기 위해서 보철물을 장착 시 반복하여 나사를 조여주거나 정기검 진 시 나사를 조여주는 방법 등이 제시되고 있다. ${ }^{20}$ 그리 고 나사의 마모, 소성변형, 피로누적 등을 고려하여 정 기적으로 새로운 나사로 교체해 주는 방법도 권장되고 있다. ${ }^{13}$ 하지만 반복하여 나사를 조이는 것은 나사의 마 모와 변형 등의 가능성이 있고, 나사의 피로를 증가시키 는 우려가 있다..$^{6-9}$ 또한 적절한 반복 조임의 간격이나 나 사의 교체 주기 등에 대해서 아직 구체적으로 제시된 바
가 없다. ${ }^{6-9}$

본 증례에서는 지대주나 지대주 나사가 파절된 경우 에서 고정체의 손상 없이 성공적으로 파절편 등을 제거 하는 방법 등에 대해 서술하였다. 위에 보고한 증례들에 서 공통적으로 나사가 파절되기 전에 나사가 풀려 있었 고 환자들은 정기검진을 받고 있지 않았다. 또한 파절편 등은 성공적으로 제거되었지만, 지대주가 손상되거나 분실되어 모두 새로운 보철물의 제작이 필요하였다. 적 절한 정기검진이 시행되었다면 나사파절의 합병증을 예 방할 수 있는 기회가 있었고, 보철물 재제작의 가능성을 줄일 수 있었을 것이라 사료된다.

\section{결론}

임플란트 치료에서 나사의 풀림이나 파절 등의 기술 적 합병증을 예방하기 위해서는 진단단계에서부터 치료 계획 수립, 임상 및 수복물의 제작 등의 일련의 과정들 이 적절하게 수행되어야 하는 것이 가장 중요하다. 그뿐 아니라 정기적인 경과관찰을 통해 합병증의 발생 가능 성을 최소화하는 것이 필요하다. 그럼에도 불구하고 나 사의 파절을 완전히 차단할 수 없는데, 임상가는 각 증 례에 따라 대처할 수 있는 적절한 방법을 숙지하는 것이 필요하다.

\section{References}

1. Pjetursson BE, Tan K, Lang NP, Brägger U, Egger $\mathrm{M}$, Zwahlen M. A systematic review of the survival and complication rates of fixed partial dentures (FPDs) after an observation period of at least 5 years. Clin Oral Implants Res 2004;15:625-42.

2. Pjetursson BE, Thoma D, Jung R, Zwahlen M, Zembic A. A systematic review of the survival and complication rates of implant-supported fixed dental prostheses (FDPs) after a mean observation period of at least 5 years. Clin Oral Implants Res 2012;23 Suppl 6:22-38.

3. Carlson B, Carlsson GE. Prosthodontic complications in osseointegrated dental implant treatment. Int J Oral Maxillofac Implants 1994;9:90-4.

4. Sailer I, Mühlemann S, Zwahlen M, Hämmerle CH, Schneider D. Cemented and screw-retained implant reconstructions: a systematic review of the survival 
and complication rates. Clin Oral Implants Res 2012;23 Suppl 6:163-201.

5. Theoharidou A, Petridis HP, Tzannas K, Garefis P. Abutment screw loosening in single-implant restorations: a systematic review. Int J Oral Maxillofac Implants 2008;23:681-90.

6. Al Jabbari YS, Fournelle R, Ziebert G, Toth J, Iacopino AM. Mechanical behavior and failure analysis of prosthetic retaining screws after long-term use in vivo. Part 1: Characterization of adhesive wear and structure of retaining screws. J Prosthodont 2008;17:168-80.

7. Al Jabbari Y, Fournelle R, Ziebert G, Toth J, Iacopino A. Mechanical behavior and failure analysis of prosthetic retaining screws after long-term use in vivo. Part 2: Metallurgical and microhardness analysis. J Prosthodont 2008;17:181-91.

8. Al Jabbari YS, Fournelle R, Ziebert G, Toth J, Iacopino AM. Mechanical behavior and failure analysis of prosthetic retaining screws after long-term use in vivo. Part 3: Preload and tensile fracture load testing. J Prosthodont 2008;17:192-200.

9. Al Jabbari YS, Fournelle R, Ziebert G, Toth J, Iacopino AM. Mechanical behavior and failure analysis of prosthetic retaining screws after long-term use in vivo. Part 4: Failure analysis of 10 fractured retaining screws retrieved from three patients. J Prosthodont 2008;17:201-10.

10. Williamson RT, Robinson FG. Retrieval technique for fractured implant screws. J Prosthet Dent 2001; 86:549-50.

11. Maalhagh-Fard A, Jacobs LC. Retrieval of a stripped abutment screw: a clinical report. J Pros- thet Dent 2010;104:212-5.

12. Satterthwaite J, Rickman L. Retrieval of a fractured abutment screw thread from an implant: a case report. Br Dent J 2008;204:177-80.

13. Nergiz I, Schmage P, Shahin R. Removal of a fractured implant abutment screw: a clinical report. J Prosthet Dent 2004;91:513-7.

14. Walia MS, Arora S, Luthra R, Walia PK. Removal of fractured dental implant screw using a new technique: a case report. J Oral Implantol 2012;38:74750.

15. Taira Y, Sawase T. A modified technique for removing a failed abutment screw from an implant with a custom guide tube. J Oral Implantol 2012;38:165-9.

16. Kurt M, Güler AU, Duran I. A technique for removal of a fractured implant abutment screw. J Oral Implantol 2013;39:723-5.

17. Yilmaz B, McGlumphy E. A technique to retrieve fractured implant screws. J Prosthet Dent 2011;105: 137-8.

18. Pow EH, Wat PY. A technique for salvaging an implant-supported crown with a fractured abutment screw. J Prosthet Dent 2006;95:169-70.

19. Bakaeen LG, Winkler S, Neff PA. The effect of implant diameter, restoration design, and occlusal table variations on screw loosening of posterior single-tooth implant restorations. J Oral Implantol 2001;27:63-72.

20. Tzenakis GK, Nagy WW, Fournelle RA, Dhuru VB. The effect of repeated torque and salivary contamination on the preload of slotted gold implant prosthetic screws. J Prosthet Dent 2002;88:183-91. 


\section{파절된 임플란트 나사의 제거: 증례보고}

\section{김태수, 이재현, 이원섭, 이수영*}

가톨릭대학교 서울성모치과병원 치과보철과

임플란트 수복물의 기계적 실패 요인들 중 가장 잦은 빈도를 보이는 것은 지대주 나사의 풀림이나 파절로 알려져 있다. 이렇게 지대주나, 나사가 파절된 경우 그 잔사들을 임플란트 고정체의 손상 없이 완전히 제거해야만 한다. 때로는 잔사 들을 제거할 수 없는 경우나 제거 과정에서 고정체와 나사를 연결하는 부위가 손상되어 임플란트를 지속하여 사용할 수 없는 경우가 발생하여 임상가를 곤란하게 만드는 경우가 있다. 본 증례보고에서는 각기 다른 세가지 임상상황에서 임플란트 고정체의 손상 없이 성공적으로 파절편을 제거한 사례들을 보고하고 나사가 파절된 임상상황에서 대처할 수 있는 방법들에 대해 고찰해 보고자 한다.

(구강회복응용과학지 2015;31 (1):60-6)

주요어: 임플란트; 나사파절; 지대주파절; 나사제거; 나사풀림 